\title{
PERUMUSAN STRATEGI BISNIS UNTUK MENINGKATKAN DAYA SAING PADA TOKO BANGUNAN XYZ
}

\author{
Nianzhi \\ Program Studi Magister Manajemen Universitas Tarumanagara \\ nianzhi100@gmail.com
}

\begin{abstract}
This research was conducted to find out what business strategies are the most appropriate for XYZ Building Stores to use to compete with other building retail stores. This study applies a qualitative method, by conducting interviews and observations by directly reviewing the subject of the study. The analytical method carried out consists of input stage, mathcing stage, and decision stage. Data that has been collected from the XYZ Building Shop is included in the input stage which consists of an EFE matrix and an IFE matrix. The matching stage that consisting of SWOT matrix, will focus on creating alternative strategies. The decision stage uses QSPM to determine the most appropriate strategy for XYZ building stores objectively. After analyzing the existing data, it is known that the market penetration strategy is the most appropriate strategy for XYZ building stores, besides that the market development strategy can also be chosen because the scores obtained by the two strategies are not too far apart.
\end{abstract}

Abstrak : Penelitian ini dilakukan untuk mengetahui strategi bisnis apa yang paling tepat untuk digunakan Toko Bangunan XYZ agar dapat bersaing dengan toko ritel bangunan lainnya. Penelitian ini menerapkan metode kualitatif, dengan melakukan wawancara serta observasi dengan meninjau secara langsung subjek penelitian. Metode analisis yang dilakukan terdiri dari input stage, mathcing stage, dan decision stage. Data yang telah dikumpulkan dari Toko Bangunan XYZ dimasukkan dalam input stage yang terdiri dari EFE matrix dan IFE matrix. Pada matching stage yang terdiri dari SWOT matrix akan berfokus pada penciptaan strategi alternatif. Tahap decision stage menggunakan QSPM untuk menentukan strategi yang paling tepat untuk toko bangunan XYZ secara objektif. Setelah melakukan analisis dari data yang ada, diketahui bahwa strategi market penetration merupakan strategi yang paling tepat bagi toko bangunan XYZ, selain itu strategi market development juga dapat dijadikan pilihan dikarenakan score yang diperoleh kedua strategi tersebut tidak berbeda jauh.

Keywords : Strategy Management, Quantitative Strategic Planning Matrix, Building Retail Store

\section{Pendahuluan}

Pertumbuhan jumlah penduduk selalu mengalami peningkatan dari waktu ke waktu, termasuk di Indonesia yang merupakan salah satu negara dengan jumlah penduduk terbanyak di dunia. Hal ini menyebabkan kebutuhan akan rumah atau properti akan selalu meningkat, begitu pula bisnis ritail bahan bangunan. Banyaknya pelaku bisnis retail bahan bangunan menyebabkan persaingan yang ketat dalam bisnis ini, termasuk toko XYZ yang berlokasi di Tangerang.

Toko bangunan XYZ merupakan salah satu toko yang ikut terjun dalam bisnis ritail bahan bangunan. Persaingan toko bangunan XYZ dengan pesaing lain disekitarnya lumayan ketat dikarenakan dalam radius 500 meter, terdapat tiga toko yang menjual barang sejenis. Tingginya tingkat persaingan bisnis tersebut membuat toko bangunan XYZ selalu berusaha untuk memenuhi kebutuhan para konsumen agar tetap dapat bersaing dengan competitior di sekitarnya. 
Keunggulan yang dimiliki toko bangunan XYZ dibandingkan toko bangunan di sekitarnya adalah kelengkapan barang serta lahan yang luas. Meskipun begitu, toko bangunan XYZ merupakan toko bangunan yang usianya terbilang muda bila dibandingkan dengan pesaing di sekitarnya. Sehingga toko XYZ diharuskan untuk mengetahui kekuatan dan kelemahan yang dimilikinya dan menerapkan strategi-strategi bisnis yang tepat untuk mengatasi masalah tersebut agar dapat tetap bersaing dengan competitior di sekitarnya.

Penelitian ini dilakukan pada toko bangunan XYZ dikarenakan tingginya tingkat persaingan di lingkungan toko bangunan XYZ dan dalam jurnal sebelumnya membuktikan bahwa strategi manajemen yang tepat dapat meningkatkan kinerja sebuah perusahaan UKM yang dimana perusahaan seperti ini seringkali mengabaikan kepentingan strategi manajemen sehingga menyebabkan kurangnya daya saing terhadap perusahaan lainnya.

Tujuan dari penelitian ini adalah untuk menghasilkan strategi yang tepat bagi toko bangunan XYZ dalam meningkatkan daya saing di pasar yang sesuai dengan kekuatan dan kelemahan yang dimiliki toko bangunan XYZ berdasarkan analisis lingkungan internal serta peluang dan ancaman yang dihadapi toko bangunan XYZ.

\section{Tinjauan Pustaka}

\section{Manajemen Strategi}

Menurut Robbins (2007), manajemen strategis adalah sekelompok keputusan dan tindakan manajerial yang menentukan kinerja jangka panjang organisasi. Manajemen strategis penting karena dapat membuat perbedaan dalam seberapa baik kinerja suatu organisasi dan berhubungan dengan kenyataan bahwa organisasi dari semua jenis dan ukuran menghadapi situasi yang terus berubah. Selain itu, manajemen strategis dibutuhkan oleh perusahaan kecil dengan meningkatkan kelincahan organisasi mereka untuk menambah keunggulan kompetitif dan daya saing (Qosasi, 2019).

\section{External Factor Evaluation (EFE) Matrix}

Menurut Gupta (2015), External Factor Evaluation (EFE) Matrix memungkinkan para ahli strategi untuk meringkas dan mengevaluasi ekonomi, sosial, budaya, hukum, lingkungan, teknologi, kondisi pasar dan persaingan untuk area yang dipertimbangkan.

\section{Internal Factor Evaluation (IFE) Matrix}

Menurut Gupta (2015), Internal Factor Evaluation (IFE) Matrix adalah alat yang meninjau kekuatan dan kelemahan organisasi. Matriks ini digunakan sebagai instrumen untuk mengumpulkan informasi tentang proses perencanaan strategis internal.

\section{Strength-Weakness-Opportunity-Threat Matrix (SWOT Matrix)}

Menurut David (2009), SWOT matrix adalah sebuah alat analistik yang menggunakan faktor internal dan eksternal sebagai dasar untuk menghasilkan strategi yang layak untuk dipertimbangkan. Strategi yang telah dihasilkan oleh SWOT Matrix kemudian dievaluasi menggunakan QSPM untuk menentukan strategi yang paling sesuai bagi perusahaan.

\section{Quantitative Strategic Planning Matrix (QSPM)}

Menurut David (2009), QSPM adalah, alat yang direkomendasikan bagi para ahli strategi untuk melakukan evaluasi pilihan strategi alternatif secara objektif, berdasarkan key success factor internal-eksternal yang telah didefinisikan sebelumnya.

\section{Metode Penelitian}

Metodologi penelitian pada penelitian ini menurut manfaat atau kegunaannya adalah untuk studi kasus, yang diarahkan untuk mendapatkan informasi yang dapat digunakan untuk memecahkan masalah serta rasa ingin tahu sehingga dapat melakukan sesuatu lebih baik, 
efisien dan efektif (Supranto,2012). Data yang digunakan pada penelitian ini meliputi data primer dan data sekunder. Untuk pengumpulan data primer digunakan teknik wawancara dan kuisioner terhadap pihak manajemen toko (pemilik toko, asisten pemilik, dan supervisor) serta observasi atau pengamatan secara langsung di lapangan, sedangkan untuk pengumpulan data sekunder diperoleh melalui buku keuangan, daftar pembelian barang, dan data-data lainnya yang relevan.

Menurut David (2017), terdapat beberapa tahapan dalam menganalisis dan memilih strategi, yaitu: The Input Stage yang terdiri dari External Factor Evaluation (EFE) Matrix dan Internal Factor Evaluation (IFE) Matrix, The Matching Stage yang terdiri dari StrenghtWeakness-Opportunity-Threat (SWOT) Matrix dan The Decision Stage yang terdiri dari Quantitative Strategic Planning Matrix (QSPM).

\section{Hasil Analisis Data}

Tabel 1.1 Hasil External Factor Evaluation (EFE) Matrix

\begin{tabular}{|l|c|c|c|}
\hline \multicolumn{1}{|c|}{ Faktor Eksternal } & Bobot & Rating & Nilai \\
\hline Peluang & & & \\
\hline 1. Memiliki hubungan yang baik dengan masyarakat sekitar & 0,12 & 4 & 0,48 \\
\hline 2. Tingkat inflasi yang cenderung menurun & 0,11 & 2 & 0,22 \\
\hline 3. Banyaknya masyarakat yang membutuhkan pekerjaan & 0,08 & 2 & 0,16 \\
\hline 4. Maraknya transportasi online & 0,09 & 3 & 0,27 \\
\hline 5. Banyaknya pilihan pemasok & 0,1 & 3 & 0,3 \\
\hline Ancaman & & & \\
\hline 1. Penurunan jumlah permintaan properti perumahan & 0,16 & 3 & 0,48 \\
\hline 2. Daya tawar konsumen yang tinggi & 0,07 & 4 & 0,28 \\
\hline 3. Harga produk yang fluktuatif terhadap kurs dollar & 0,1 & 1 & 0,1 \\
\hline 4. Industri online yang berkembang dengan pesat & 0,08 & 1 & 0,08 \\
\hline 5. Terjadinya perang harga & 0,09 & 3 & 0,27 \\
\hline Total & & & 2,64 \\
\hline
\end{tabular}

Berdasarkan tabel diatas dapat dilihat bahwa hasil analisis matriks EFE memperoleh nilai 2,64, yang berarti bahwa toko bangunan XYZ mendapatkan nilai diatas rata-rata. Hal ini menunjukkan bahwa perusahaan memiliki respon diatas rata-rata dalam menangkap peluang yang ada dan menghindari ancaman yang datang.

Tabel 1.2 Hasil Internal Factor Evaluation (IFE) Matrix

\begin{tabular}{|l|c|c|c|}
\hline \multicolumn{1}{|c|}{ Faktor Internal } & Bobot & Rating & Nilai \\
\hline Kekuatan & & & \\
\hline 1. Memiliki banyak customer yang loyal & 0,13 & 4 & 0,52 \\
\hline 2. Lokasi yang strategis & 0,11 & 4 & 0,44 \\
\hline 3. Kelengkapan varian produk & 0,1 & 4 & 0,4 \\
\hline 04. Memiliki lahan yang luas sebagai tempat penyimpanan barang & 0,07 & 3 & 0,21 \\
\hline 05. Mempunyai hubungan dekat dengan supplier & 0,09 & 4 & 0,36 \\
\hline Kelemahan & & & \\
\hline 1. Memiliki keterbatasan jumlah karyawan & 0,09 & 1 & 0,09 \\
\hline 2. Belum memanfaatkan promosi via internet & 0,1 & 2 & 0,2 \\
\hline $\begin{array}{l}\text { 3. Belum menggunakan sistem komputerisasi (administrasi dan } \\
\text { pengawasan) }\end{array}$ & 0,1 & 2 & 0,2 \\
\hline 4. Belum memanfaatkan fungsi toko online & 0,12 & 2 & 0,24 \\
\hline 5. Keterbatasan jumlah armada transportasi & 0,09 & 1 & 0,09 \\
\hline Total & & & 2,75 \\
\hline
\end{tabular}


Berdasarkan tabel diatas dapat dilihat bahwa hasil analisis matriks IFE memperoleh nilai 2,75 , yang berarti bahwa toko bangunan XYZ mendapatkan nilai diatas rata-rata. Hal ini menunjukkan bahwa perusahaan memiliki posisi kekuatan internal dalam persaingan yang lebih besar dibandingkan faktor kelemahannya.

Tabel 1.3 Hasil Strength-Weakness-Opportunity-Threat (SWOT) Matrix

\begin{tabular}{|c|c|c|}
\hline & $\begin{array}{l}\text { Kekuatan (Strengths) } \\
\text { 1. Memiliki banyak customer } \\
\text { yang loyal } \\
\text { 2. Lokasi yang strategis } \\
\text { 3. Kelengkapan varian produk } \\
\text { 4. Memiliki lahan yang luas } \\
\text { sebagai tempat penyimpanan } \\
\text { barang } \\
\text { 5. Mempunyai hubungan dekat } \\
\text { dengan supplier }\end{array}$ & $\begin{array}{l}\text { Kelemahan (Weaknesses) } \\
\text { 1. Memiliki keterbatasan } \\
\text { jumlah karyawan } \\
\text { 2. Belum memanfaatkan } \\
\text { promosi via internet } \\
\text { 3. Belum menggunakan sistem } \\
\text { komputerisasi (administrasi } \\
\text { dan pengawasan) } \\
\text { 4. Belum memanfaatkan fungsi } \\
\text { toko online } \\
\text { 5. Keterbatasan jumlah armada } \\
\text { transportasi }\end{array}$ \\
\hline $\begin{array}{l}\text { Peluang (Opportunities) } \\
\text { 1. Memiliki hubungan yang } \\
\text { baik dengan masyarakat sekitar } \\
\text { 2. Tingkat inflasi yang } \\
\text { cenderung menurun } \\
\text { 3. Banyaknya masyarakat yang } \\
\text { membutuhkan pekerjaan } \\
\text { 4. Maraknya transportasi } \\
\text { online } \\
\text { 5. Banyaknya pilihan pemasok }\end{array}$ & $\begin{array}{l}\text { Strategi SO } \\
\text { 1. Penambahan inventory untuk } \\
\text { mendapatkan harga yang lebih } \\
\text { murah (S4, S5, O2) } \rightarrow \text { Market } \\
\text { Penetration Strategy \& Market } \\
\text { Development Strategy } \\
\text { 2. Menyeleksi beberapa } \\
\text { supplier yang tersedia untuk } \\
\text { mendapatkan harga beli yang } \\
\text { termurah (S5, O5) } \rightarrow \text { Market } \\
\text { Penetration Strategy \& Market } \\
\text { Development Strategy }\end{array}$ & $\begin{array}{l}\text { Strategi WO } \\
\text { 1. Menggunakan jasa } \\
\text { transportasi online untuk } \\
\text { pengiriman barang (W5, O4) } \\
\rightarrow \text { Market Penetration } \\
\text { Strategy } \\
\text { 2. Perekrutan karyawan dari } \\
\text { masyarakat sekitar (W1, O1, } \\
\text { O3) } \\
\text { 3. Penambahan armada } \\
\text { transportasi (W5, O2) } \rightarrow \\
\text { Market Penetration Strategy }\end{array}$ \\
\hline $\begin{array}{l}\text { Ancaman (Treats) } \\
\text { 1. Penurunan jumlah } \\
\text { permintaan property } \\
\text { 2. Daya tawar konsumen yang } \\
\text { tinggi } \\
\text { 3. Harga produk yang } \\
\text { fluktuatif terhadap kurs dollar } \\
\text { 4. Industri online yang } \\
\text { berkembang dengan pesat } \\
\text { 5. Terjadinya perang harga }\end{array}$ & $\begin{array}{l}\text { Strategi ST } \\
\text { 1. Membuat program khusus } \\
\text { customer loyal (S1, T2, T4, } \\
\text { T5) } \rightarrow \text { Market Penetration } \\
\text { Strategy } \\
\text { 2. Mencari produk baru dari } \\
\text { produsen lokal (S4, T2, T3) } \rightarrow \\
\text { Product Development Strategy }\end{array}$ & $\begin{array}{l}\text { Strategi WT } \\
\text { 1. Mencari pasar baru dengan } \\
\text { membuka toko online (W4, T1, } \\
\text { T4) } \rightarrow \text { Market Development } \\
\text { Strategy } \\
\text { 2. Melakukan promosi dengan } \\
\text { menggunakan media sosial } \\
(\mathrm{W} 2, \mathrm{~T} 4) \rightarrow \text { Market } \\
\text { Penetration Strategy } 3 \text {. } \\
\text { Penambahan aset berupa } \\
\text { sistem yang terkomputerisasi } \\
\text { untuk meningkatkan pelayanan } \\
\text { terhadap customer (W1, W3, } \\
\text { T2) } \rightarrow \text { Market Penetration } \\
\text { Strategy }\end{array}$ \\
\hline
\end{tabular}

Pada tabel diatas dapat dilihat alternatif-alternatif strategi yang diperoleh dari matriks SWOT kemudian diolah untuk merumuskan strategi-strategi yang dapat dipakai untuk menghadapi ancaman eksternal dan kelemahan internal yang dihadapi. Alternatif strategi yang telah diperoleh, dimasukkan ke dalam tabel QSPM, begitu juga dengan faktor kunci dan bobot yang diperoleh pada tahap masukan. 
Tabel 1.5 Hasil Quantitative Strategic Planning Matrix (QSPM)

\begin{tabular}{|l|c|c|c|c|c|}
\hline \multirow{2}{*}{ Faktor Kunci } & \multirow{2}{*}{ Bobot } & $\begin{array}{c}\text { Strategi Market Penetration } \\
\text { Attractiveness } \\
\text { Score }\end{array}$ & $\begin{array}{c}\text { Total } \\
\text { Attractiveness } \\
\text { Score }\end{array}$ & $\begin{array}{c}\text { Strategi Market Development } \\
\text { Attractiveness } \\
\text { Score }\end{array}$ & $\begin{array}{c}\text { Total } \\
\text { Attractiveness } \\
\text { Score }\end{array}$ \\
\hline Peluang 1 & 0,12 & 4 & 0,48 & 4 & 0,48 \\
\hline Peluang 2 & 0,11 & 4 & 0,44 & 3 & 0,33 \\
\hline Peluang 3 & 0,08 & 1 & 0,08 & 1 & 0,08 \\
\hline Peluang 4 & 0,09 & 3 & 0,27 & 2 & 0,18 \\
\hline Peluang 5 & 0,1 & 4 & 0,4 & 3 & 0,3 \\
\hline Ancaman 1 & 0,16 & 3 & 0,48 & 2 & 0,32 \\
\hline Ancaman 2 & 0,07 & 3 & 0,21 & 2 & 0,14 \\
\hline Ancaman 3 & 0,1 & 2 & 0,2 & 2 & 0,2 \\
\hline Ancaman 4 & 0,08 & 3 & 0,24 & 4 & 0,32 \\
\hline Ancaman 5 & 0,09 & 3 & 0,27 & 2 & 0,18 \\
\hline Kekuatan 1 & 0,13 & 4 & 0,52 & 3 & 0,39 \\
\hline Kekuatan 2 & 0,11 & 3 & 0,33 & 4 & 0,44 \\
\hline Kekuatan 3 & 0,1 & 3 & 0,3 & 4 & 0,4 \\
\hline Kekuatan 4 & 0,07 & 2 & 0,14 & 3 & 0,21 \\
\hline Kekuatan 5 & 0,09 & 2 & 0,18 & 2 & 0,18 \\
\hline Kelemahan 1 & 0,09 & 1 & 0,09 & 1 & 0,09 \\
\hline Kelemahan 2 & 0,1 & 3 & 0,3 & 4 & 0,4 \\
\hline Kelemahan 3 & 0,1 & 3 & 0,3 & 2 & 0,2 \\
\hline Kelemahan 4 & 0,12 & 2 & 0,24 & 4 & 0,48 \\
\hline Kelemahan 5 & 0,09 & 2 & 0,18 & 1 & 0,09 \\
\hline Total & & & 5,65 & & 5,41 \\
\hline
\end{tabular}

Berdasarkan tabel diatas, dapat dilihat bahwa strategi market penetration memperoleh nilai 5.65 dan strategi market development memperoleh nilai 5.41. Maka dapat diambil kesimpulan bahwa strategi market penetration merupakan strategi terbaik bagi toko bangunan $\mathrm{XYZ}$, sedangkan strategi market development dapat digunakan sebagai strategi pendukung.

\section{Kesimpulan dan Saran}

Dari hasil penelitian pada bab pembahasan, menunjukkan bahwa strategi yang paling efektif bagi toko bangunan XYZ untuk meningkatkan daya saing adalah menggunakan strategi market penetration, dengan score 5.65. Strategi penetrasi pasar terdiri dari upaya untuk mempertahankan pelanggan yang ada dan mempengaruhi para pelanggan agar membeli lebih banyak. Contohnya adalah dengan melakukan iklan berupa pembuatan banner di ruas jalan atau dengan melakukan iklan di media sosial. Selain itu strategi market development juga dapat dipertimbangkan, dikarenakan hasil score yang diperoleh tidak berbeda terlalu jauh yaitu sebesar 5.41. Strategi penetrasi pasar terdiri dari upaya untuk mencari pelanggan baru melalui perluasan area pemasaran secara geografis. Contohnya adalah dapat juga dengan menggunakan iklan yang berisi informasi mengenai lokasi dan barang yang dijual toko bangunan XYZ.

Dari hasil kesimpulan diatas, maka toko bangunan XYZ disarankan untuk menerapkan strategi bisnis yang baru agar perusahaan dapat lebih berkembang dan dapat meningkatkan daya saing terhadap toko bangunan sejenis di sekitar toko bangunan XYZ. Beberapa strategi yang dapat dipertimbangkan seperti strategi penetrasi pasar untuk mempertahankan pelanggan yang ada dan mempengaruhi para pelanggan agar membeli lebih banyak, dan strategi pengembangan pasar untuk memperoleh pasar baru diluar pasar yang telah dimiliki sekarang secara geografis. Selain itu, toko bangunan XYZ juga dapat mencoba untuk menyalurkan produknya ke berbagai media penjualan online yang ada. 


\section{Daftar Pustaka}

David, M.E., David, Forest R., \& David, Fred R. (2009). The quantitative strategic planning matrix (QSPM) applied to retail computer store. The Coastal Business Journal. 42-52.

David, Fred R. \& David, Forest R. (2017). Strategic Management: A Competitive Advantage Approach, Concepts and Cases. 16th Edn. Pearson.

Gupta, M., Shri, C., \& Agrawal, A. (2015). Strategy Formulation for Performance Improvement of Indian Corrugated Industry: An Application of SWOT Analysis and QSPM Matrix. Journal of Applied Packaging Research: Vol. 7: No. 3, 60-75.

Qosasi, A., Permana, E., Muftiadi, A., Purnomo, M., \& Maulina, E. (2019). Building SMEs' Competitie Advantage and the Organizational Agility of Apparel Retailers in Indonesia: The role of ICT as an Initial Trigger. Gadjah Mada International Journal of Business: Vol. 21: No. 1, 69-90.

Robbins, S \& Coulter, M. (2007). Manajemen. Edisi Kedelapan. Jakarta : PT Indeks. Supranto, J. (2012). Metode Riset. Jakarta: Rineka Cipta. 